\title{
Knowledge Management in Historic Buildings Conservation Organizations
}

\author{
Salem M. Tarhuni \\ Department of Architecture, Faculty of Engineering \\ Tishk International University \\ Erbil, Iraq \\ salem.mokhtar@tiu.edu.iq
}

\author{
John Kamara \\ School of Architecture, Planning and Landscape \\ Newcastle University \\ Newcastle, UK \\ john.kamara@ncl.ac.uk
}

\begin{abstract}
This paper aims to investigate the key factors that affect the management of knowledge in the context of the Management of Historic Cities Bureau Organization (MHCB) in Libya. An approach of qualitative research was adopted for collecting and analyzing data. Multiple methods were used for collecting data and information, including interviews, observations, and analysis of organizational documents. The findings demonstrated that a balance between people-based and explicit knowledge-based approaches are required to effectively manage knowledge in organizations. Furthermore, fourteen factors affect knowledge management in the MHCB. They include individual and organizational factors in addition to factors relevant to knowledge and its management. The main factors that differentiate knowledge management in historic building conservation organizations are the type of knowledge, the proximity of the organization's headquarters to Historic Buildings and, the external sources of knowledge in addition to the social/religious factor. The proposed model for studying and understanding knowledge management in historic buildings organizations provides a base reference for similar organizations. It enables decision-makers in such institutions to study and understand Knowledge Management in order to apply effective Knowledge Management to improve their organization's performance.
\end{abstract}

Keywords - Historic Buildings; Organizations; Libya; Knowledge Management; Conservation; Qualitative Research

\section{I- INTRODUCTION}

The concept of knowledge management (KM) is relatively new. Some fields started dealing with KM before others. The first fields were business administration, information systems, and library and information sciences, while other fields have recently followed them [1]. In the field of construction, the concept of KM was mostly studied in the 2000s [2]. However, KM was not studied until approximately 10 years later in the field of architectural conservation. Chutinam [3] developed an integrated plan with a secondary general part for $\mathrm{KM}$ to optimize the structure of the organization that is responsible for the effective promotion of heritage property and applied it for a historic park in Thailand. Also, Taghizadeh et al. [4] developed a KM model system for historic buildings restoration projects. Moreover, Tarhuni studied the effect of technical employees' turnover on historic buildings conservation organizations' performance [5].
Most governments have established institutions for conserving their architectural heritage. The Libyan government established the Institution of Management of Historic Cities Bureau (MHCB), whose mission was the conservation of historic buildings [6]. This paper aims to investigate the key factors that affect the management knowledge in the context of the MHCB.

\section{II- THE ORGANISATIONS THAT CARE FOR HISTORIC BUILDINGS}

Historic buildings (HBs) are regarded as a form of national heritage for countries and should therefore be conserved. Managing HBs is a continual process often conducted by responsible organizations that are not-for-profit and noncompetitive. Heritage focused organisations are those organisations where the care for historic buildings is the core business activity. Dann et al [7] mentioned these three organisations:

- Building preservation trusts

- Organisations with national standing in the field of heritage conservation who also manage significant portfolios of historic buildings

- Large government organisations with a stock of historic buildings - some with a degree of statutory responsibility

Building preservation trusts could be considered as public organisations that are supported primarily through public funds and often do not have adequate resources. As Dewoolkar et al. [8] stated, that "often these communities or organizations do not have adequate resources (technical expertise, funding) for even preliminary engineering services."

Regarding national organisations in the field of built heritage conservation who also manage significant portfolios of historic buildings, Pickard [9] stated that:

"The management of historic centres requires a political commitment both at a national level, through financial support mechanisms and regulatory and legislative provisions, and at the local level, where municipal action can be directed in association or in partnership with other agencies and with the private sector through an integrated process."

Finally, government institutions offer general advice and create policies and regulations regarding HBs conservation 
[10]. Also, they are concerned with preserving and studying the built heritage. The most significant asset for heritage focused organizations to achieve their objectives and facilitate the continuous improvement of their performance is knowledge, as scholars and charters stress the development knowledge of the staff and organizations in this field [11, 12, 13, 14]. For instance, the Australian Burra Charter stated that "conservation should make use of all the knowledge, skills and disciplines which can contribute to the study and care of the place" [14].

\section{KNOWLEDGE MANAGEMENT AND ITS MAIN APPROACHES}

The concept of knowledge management (KM) is associated with various organizational subjects such as organisational learning, human resource management, research and development activities, document management, and information technology. Knowledge management as a process has been defined as:

"A process that helps organisations find, select, organize, disseminate and transfer information and expertise necessary for activities such as problemsolving, dynamic learning, strategic planning, and decision making. [15]

However, knowledge management is not an end in itself; its advantages include enhancing performance, improving the capabilities of the organization's human resources, problemsolving, learning, strategic planning, and decision making within the organization [1], [15], [16], [17].

Knowledge Management (KM) in organizations has been influenced by the theory of Nonaka and Takeuchi [18], which contains four distinct modes of interaction between tacit (personal) knowledge and explicit (organizational) knowledge. The main approaches in the field of knowledge management are people-based and explicit-based KM approaches, both of which are important for organizations as they add value and address their problems.

The people-based KM approach concentrates more on socialization in terms of the transfer of tacit to tacit knowledge between individuals, and internalization in terms of the transfer of explicit to tacit knowledge [18]. Furthermore, the people-based KM approach focuses on people who deal with knowledge in their work, and how people within organizations capture and share the knowledge based on the concept that there is a risk that tacit knowledge is lost in organizations if it is not managed. As Rowley emphasized, tacit knowledge that resides in individuals' minds should be managed, as he stated that "opportunities for the exchange of tacit knowledge cannot be left to chance and need to be supported and facilitated [19]. Moreover, people-based KM addresses an organization's human resources issues. People-based $\mathrm{KM}$ is relevant to organizations' employees when these employees need to create, share, look for and use knowledge in their daily work [20]. However, such employees are different according to their background, culture and, abilities, and this means that a strategy for studying KM should be context-specific.

The other main approach in the field of knowledge management is the explicit-based $\mathrm{KM}$ approach, which concentrates more on externalization in terms of the transformation of tacit to explicit knowledge, and combination in terms of the transfer of explicit to other explicit knowledge [18]. Regarding this approach, Sheehan et al [21] mentioned that this is "an explicit approach focusing on capturing knowledge in documents, database, intranets, etc." This approach tends "to be heavily technology-focused and is concerned with the management of explicit knowledge" [22].

\section{METHODOLOGY}

An approach of qualitative research was adopted for collecting and analysing data and information. Multiple methods were used including interviews, and observations, in addition to reviewing organizational documents. Qualitative research allows the subjects being studied to give much 'richer' and valuable insights. Multiple sources of evidences were adopted for collection data and information. This provided protection against threats to the validity of the collected data and findings [23].

Semi-structured interviews were conducted in Tripoli with twenty interviewees representing various parties in the MHCB and local HB conservation field. The criteria for choosing the interviewees included: the interviewee knowing about the $\mathrm{MHCB}$ and local HB conservation work with experience of 10 years or more in the field. Also, in terms of the employees, the selection process considered a variety of levels to better reflect the opinions regarding the existing situation in the MHCB context.

Furthermore, the observations that were conducted in the MHCB context included observation of on-task behavior and the physical space in the MHCB. Moreover, The institutional documents that were reviewed were employees' records, relevant regulations, written procedures, $\mathrm{HB}$ drawings, and previous studies. For analyzing qualitative data, a thematic analysis process was used. The findings were gathered and discussed all together and validated by cross-checking the fieldwork findings against the wider literature.

\section{FINDINGS AND Discussions}

Throughout the research, it appears that the people-based and the explicit knowledge-based KM approaches are essential for managing knowledge in organizations. The research investigated the key factors that affect the management of knowledge in the MHCB context and concluded in a proposed model for studying and understanding $\mathrm{KM}$ in organizations Fig. 1.

Fourteen factors were identified, discussed, and validated by cross-checking the fieldwork findings against the wider literature. They include factors relevant to knowledge and its management, also, factors relevant to individuals and organizations 


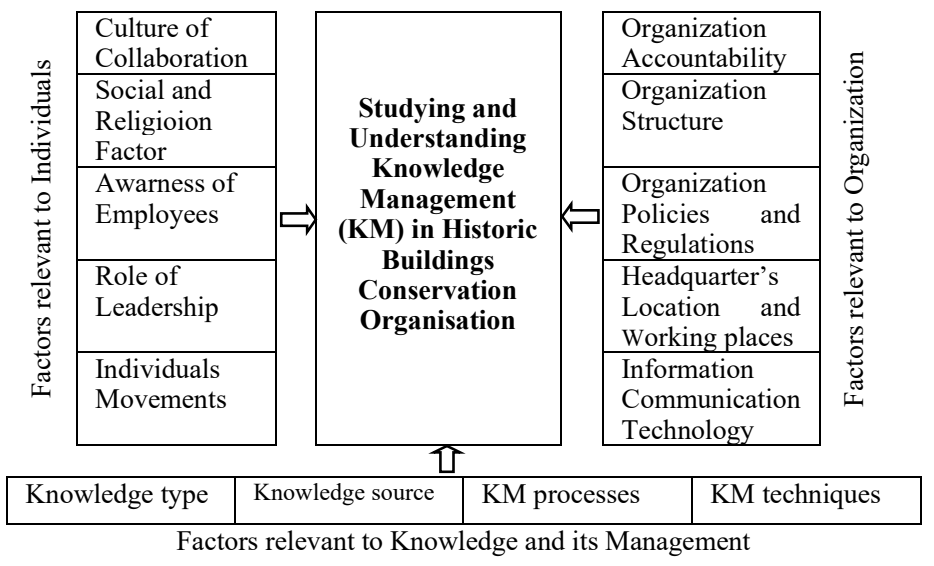

Fig. 1: A proposed model for studying and understanding $\mathrm{KM}$ in $\mathrm{HBs}$ conservation organizations

\section{A. Factors Relevant to Knowledge and its Management in the MHCB's Context}

1) Type of Knowledge in the MHCB:

The main knowledge aspects in the MHCB are $\mathrm{HB}$ values knowledge, HB conservation technical knowledge, and HB conservation management knowledge. The knowledge regarding the cultural value of $\mathrm{HBs}$ is a sub-factor that differentiates managing knowledge in $\mathrm{HB}$ conservation organizations from other construction organizations. This complies with the wider literature; knowledge and its context may have "value and meaning in one context [and...] little or no meaning in another" [24]. Regarding conservation management knowledge, it was noted by a senior technical employee in the MHCB that the lack of knowledge regarding preparing project documents and tendering is largely attributed to the fact that the MHCB was an implementer for conservation works and it rarely prepares the contract documents for reparation projects. This indicated that the importance and the need for some knowledge aspects in organizations could be changed according to changes in organizational circumstances and the priorities of work.

\section{2) Knowledge Sources:}

Organizational learning processes include sharing internal knowledge and adopting knowledge in terms of importing knowledge from an external source [25], [26]. Commercial or competition issues are not $\mathrm{KM}$ advantages for $\mathrm{HB}$ conservation organizations; the advantages are mainly cultural. Accordingly, dependence on external knowledge sources is common. In the MHCB, external knowledge is required to cover internal shortages. The international heritage charters call for the dissemination of knowledge [14]. This facilitates the opportunities for the exchange of knowledge between relevant institutions locally and internationally. Also, local interested people and architects, and engineers who have left the MHCB after significant years of practical experience, are willing to share their knowledge regarding HBs and their conservation. External knowledge sources differentiate $\mathrm{KM}$ in $\mathrm{HB}$ conservation organizations from business organizations.

\section{3) Knowledge Management Processes:}

Although the MHCB does not apply KM formally, some activities are applied for capturing, storing, and disseminating knowledge. However, the cumulated tacit knowledge has not been transferred to an explicit form. Also, there are no criteria for what is included in the MHCB's database. For instance, it has not included the lessons learned from previously resolved technical problems. This contradicts the conservation principles regarding the necessity of the precise reporting of any action relevant to HB conservation [14], [27].

4) Knowledge Management techniques in the MHCB: In the MHCB, tacit knowledge was managed through the application of several techniques: trial and error, lectures and presentations, the rotation work system, training, teamwork, and face-to-face interaction. The debate continues regarding the risk of applying trial and error techniques in conservation work. One opinion is that such a technique can be applied; even the results are not proven. This opinion is considered by a specialist in the field of HB conservation, Feilden [28], who stated that "it must be recognized that some problems are unique and have to be solved from first principles on a trialand-error basis." However, the other opinion claims that HBs are sensitive and should be treated with care [14], [19],[27], [29]. Furthermore, because of the shortage of architects and engineers, the MHCB has been forced to apply the rotation work system technique. This technique might lead to a negative impact on performance because unqualified technicians become decision-makers. This contradicts with conservation principles, as ICOMOS [14] stated that because of the value of historic buildings, their conservation work should only be undertaken by those with the appropriate knowledge and skills. Moreover, the constraints related to training in the MHCB include limited local training courses in the field of HB conservation and a lack of knowledge regarding the details of required training courses and who provides them. Finally, the face-to-face interaction technique in terms of formal meetings and informal discussions has been applied in the MHCB. It is defined as a technique that achieves socialization in terms of converting tacit knowledge into another tacit knowledge [30]. The context in the technical affairs department provided opportunities for meetings and sharing knowledge. However, formal meetings rarely occur in the MHCB and informal discussions tend to occur between each gender separately due to social/religious reasons.

\section{B. The Organizational Factors Affecting KM in the MHCB's Context}

\section{1) The MHCB's Accountability:}

The MHCB is a governmental organization whose core business activity involves care for HBs. Since its establishment in 1986, the accountability of the MHCB has changed five times. The last accountability change of the MHCB was from the Facilities Ministry to the Tourism 
Ministry. The different strategy of the Tourism Ministry has impacted on the organizational structure and led to the MHCB becoming managerial-oriented instead of an implementation-oriented organization. This change affected the MHCB's performance as it led to the need for different knowledge, such as knowledge regarding contracting processes. Also, it has affected some architects and engineers, who ultimately left the MHCB along with their knowledge.

2) The Organizational Structure of the $M H C B$ :

In the $\mathrm{MHCB}$, the organizational structure includes four departments and numerous sections. The organizational structure (at the level of sections) supports personal interactions and communities of practice between technical sections in the technical affairs department. This complies with the broad literature, which calls for a flexible organizational structure for successful KM [31]. However, an inflexible organizational structure (at the level of departments) has led to the restriction of knowledge sharing among employees in different departments. The difficulties regarding contact between employees and exchanging documents in different departments can be attributed to organizational structure. This includes:

- The restrictions that employees should not leave their departments

- $\quad$ Poor coordination between departments that leads to delay as a result of routine and the condition of obtaining consent from the head of the department.

- Lack of willingness to collaborate and the monopoly of some information.

The situation of the organizational structure in the MHCB at the departmental level contradicts the ideal situation mentioned in the wider literature. For instance, Kooh and Altmann [32] emphasized that organizations must adopt structures that allow them to create and transfer more knowledge. Also, Anantatmula [33] stated that:

"The organization should have a structure which facilitates personal interactions and supports communities of practice to capture tacit and explicit knowledge within the organization".

3) The Effect of the MHCB's Policies and Governmental Regulations on KM:

Lack of staff motivational policies has led to the high rate of technical staff leaving MHCB (see section C5). This situation contradicts the wider literature, as one KM goal is to ensure that knowledge-workers remain with the company through the implementation of staff motivation policies [34]. Scholars in the field of $\mathrm{HB}$ conservation call for appropriate outsourcing policies to ensure that the organization has the required skills available [35]. Also, in the MHCB there are legal constraints in contacting foreign institutions for cooperation. However, developing organizational norms and values that support the creation and sharing of knowledge is essential for successful KM within organizations [36], [37].

4) The Headquarters' Location and Working Places: The MHCB's headquarters is a refurbished HB located in the centre of the old city of Tripoli, which means that it is an idea for easily accessing and mentoring other HBs. This provides the chance to observe what occurs in the HBs during the period after refurbishment. The fact that the employees coexist with HBs enables them to develop good common knowledge. The term 'common knowledge' means "knowledge that is known to all members of a firm. The idea of common knowledge is very similar to the idea of common sense, which helps to conduct the work in an organization by providing common grounds for all workers" [38]. This factor differentiates $\mathrm{KM}$ in $\mathrm{HB}$ conservation organizations from other organizations. Furthermore, the workplaces are divided between male and female employees. A senior technical employee stated that the "offices' pattern in the MHCB is conducive for meetings and exchanging knowledge." This shared context provides a good environment for sharing knowledge among employees. Scholars have emphasized that sharing a workplace supports the referral of knowledge and provides face-to-face contact and offers a common language that enables individuals to understand each other's actions and backgrounds [39], [40],[ 41].

5) Information Communication Technologies (ICT) in the $M H C B$ :

The software used in the MHCB largely consists of computer programs, which have not been contributed effectively to managing knowledge. Furthermore, storing documents in both, papers and digital forms is commonly practiced to avoid their loss. The existence and use of ICT facilities for managing knowledge in the MHCB do not sufficiently comply with the role of ICT for KM, as mentioned in the wider literature. ICT plays an important role in facilitating $\mathrm{KM}$ processes as it is required for effectively codifying, storing, and retrieving knowledge. Also, it supports accessing existing information and connecting or directing a user that has a problem or question to knowledge repositories or experts [42].

\section{Factors Related to Individuals Affecting KM in the $M H C B$ 's Context}

1) The Culture of Collaboration in the $M H C B$ :

The collaborative climate is available in the technical affairs department. It is acceptable to ask for help and reasonable to make mistakes, senior employees have transferred their knowledge to juniors and employees tend to contact colleagues as a first choice for obtaining knowledge when facing problems. These results indicate positive points that this context facilitates knowledge sharing among technical employees in the MHCB. These results mostly comply with the four points that should be provided in organizations for the creation of a knowledge-sharing culture [21]. However, the findings indicated that there is some weakness in the content of existing shared knowledge in the field of $\mathrm{HBs}$ ' conservation and technical employees do not actively seek and apply new learning.

\section{2) Social and Religious Factor:}

The employees' working places were divided between male and female employees and the informal discussions tended to occur between each gender separately in their own halls. This is attributed to social and religious reasons. The head of the 
architectural studies section (female) explained that in lectures, presentations, and meetings, effective discussions occur between the two genders. Also, asking questions is common between male and female employees. However, it seems that exchanging knowledge between genders has not been previously studied in the field of knowledge management. This factor differentiates KM organizations in conservative societies from other organizations.

\section{3) Awareness of Employees Regarding $K M$ in the} MHCB Context:

The findings indicated that the MHCB's employees are aware of the need to develop their knowledge and, achieving the goal of KM through the cooperation between the employees and their institution. This complies with the wider literature, which mentions that an awareness that knowledge transfer has occurred or is needed is essential for KM [43]. Furthermore, more satisfaction among employees will be achieved when KM is applied in organizations [44].

\section{4) The Role of the MHCB's Leadership in Managing} Knowledge:

The current head was keen (to some extent) to develop staff abilities and knowledge. This can be seen in the provision of ICT facilities, some specialized training courses, and the encouragement of discussions. This to some extent complies with the wider literature. For instance, Anantatmula stated that:

"The leader plays a critical role in securing funds and building the technology infrastructure to accomplish KM goals and objectives. Capable leaders garner the support of the top management and influence the collaborative culture [33].

However, no leader/s have been assigned for guiding the KM processes in the MHCB. This contradicts the role of leadership as mentioned in the wider literature, which emphasizes that leadership guidance of knowledge workers can facilitate KM processes within the organization. For instance, Murthy and Panchal [37] stated that a competent and committed leader/s should guide a group of knowledge workers who "facilitate, curate, and disseminate knowledge within the organization". Also, Anantatmula [33] stated: "organizations will experience better results if they choose a leader before a detailed plan for KM initiative is developed and implemented".

\section{5) Individuals in the $M H C B$ and their Movement:}

The MHCB suffers from the departure of technical employees. The loss of senior staff members from the HB conservation organization represents an irreparable loss. This is because of a lack of specialists in this field. It has caused the loss of tacit and explicit knowledge obtained from years of work experience.

The senior members of staff working in the MHCB are considered as sources of knowledge. They have acquired knowledge regarding HBs and their conservation from years of accumulated experiences. Feilden [28] stated that staying in the same job is an important factor for staff developing thorough knowledge. However, the MHCB's administrative records showed that the average of leaving among technical staff is 2.3 yearly. This situation of technical employees leaving represents a threat to the MHCB and has caused a loss of tacit knowledge that was accumulated from years of work experience in the field of HB conservation, and also of explicit knowledge they may have or have access to. Furthermore, there is no continuous knowledge transfer in addition to wasting the time and costs spent on developing their skills and knowledge. Egbu et al. [45], Sheehan et al. [46], and Joe et al. [47] warned of the risks of senior staff leaving with their acquired knowledge. In the field of HB conservation, staff turnover represents an irreparable loss, particularly in the MHCB, because the number of specialists is very limited.

\section{CONCLUSIONS}

An investigation has been performed on the current conditions for dealing with knowledge in the MHCB to identify the key factors that affect the management of knowledge in such organizations. The findings demonstrated that a balance between people-based and explicit knowledgebased approaches is required to effectively manage knowledge in organizations.

Fourteen factors that affect $\mathrm{KM}$ in organizations were investigated in the MHCB. They include factors relevant to individuals and organizations in addition to factors relevant to knowledge and its management. There are numerous factors differentiate $\mathrm{KM}$ in HBs conservation organizations from other organizations. The first one is the type of knowledge, which includes the cultural value of HBs. Also, the importance and the need for some knowledge aspects in organizations could be changed according to changes in organizational circumstances and the priorities of work. The second factor is headquarters' location. The proximity of the organization's headquarters to HBs affects the acquisition of knowledge through the monitoring of HBs, which enables the technical employees to develop their common knowledge. Thirdly, the unique aspect of the field of heritage conservation is regarding external sources of knowledge. The international heritage charters call for the dissemination of knowledge and, local interested people are often willing to share their knowledge regarding HBs and their conservation. Moreover, the factor that differentiates KM in organizations in conservative societies from other organizations is the social/religious factor, as informal knowledge sharing activities tend to occur between each gender separately. Exchanging knowledge between genders has not been previously studied in the field of knowledge management.

Finally, this research could be considered as the start of studying knowledge management in historic buildings conservation organizations. it has raised several issues concerning historic buildings conservation and knowledge management and fills a gap in the literature and adds support to the previous knowledge management researches. Also, the proposed model for studying and understanding knowledge management in the organization provides a base reference for the application of KM in historic buildings organization and 
similar organizations in the same context. It enables decisionmakers in such institutions to apply effective KM to improve their organization's performance.

\section{REFERENCES}

[1] S.Vector, (2008) Knowledge Management Available at http://www.vectorstudy.com/management_topics/knowledge_management. htm.

[2] C. Egbu, and H. Robinson, (2005) 'Construction as a Knowledge-Based Industry', in Anumba, J., Egbu, C. and. Carrillo, P (ed.) Knowledge management in Construction. Oxford: Blackwell Publishing Ltd, pp. 31-49.

[3] S. Chutinan, (2008) Cultural heritage interpretation, management, and promotion: phimai historical park, Ph.D. Thesis, Silpakorn University, Bangkok, Thailand.

[4] K. Taghizadeh, E. Mokhtari, and M. Sari, (2014) Practical approach to knowledge management implementation in historic buildings restoration Management Science Letters 4 pp. 2555-2570

[5] S. Tarhuni, (2016) 'The Impacts of Technical Employees' Departure on Historic Buildings Organizations' Performance', Universal Journal of $\begin{array}{lllll}\text { Management } & 4(6), 367 & - & 374 . & \text { Available }\end{array}$ at:http:/www.hrpub.org/journals/article_info.php?aid=3833

[6] GPC (1985) Libyan Governmental Implementation decision number 3 regarding the establishment of the project for the organization and management of the old city of Tripoli. Governmental Press, Tripoli, Libya

[7] N. Dann, D. Worthing, S. Bond (1999) 'conservation maintenance management Establishing a research agenda', Structural Survey, 17(3).

[8] Dewoolkar, M.M., Porter, D. and Hayden, N.J. (2011) 'Service-Learning in Engineering Education and Heritage Preservation', International Journal of Architectural Heritage, 5(6), pp. 613-628. [Online]. Available at: http://www.tandfonline.com/doi/abs/10.1080/15583051003792864.

[9] R. Pickard,. (2001) Management of Historic Centres. London: spon press.

[10] C. Macky, V. Rickard, and N. Hughes, (2012) 'Resources for the on-going care for heritage housing in New Zealand - a public proposal for the private realm', 3rd International Conference on Heritage and Sustainable Development. Porto, Portugal, June 19-22. Green Lines Institute for Sustainable Development, pp. 1919-1930.

[11] D. Lazarus, (2007) 'Maintenance of heritage architecture: implementation and practice', WIT Transactions on The Built Environment, 95, pp. 319 328.

[12] I. Wafa, (2007) Architectural heritage conservation: the purposes and the principles, The 1st symposium under title: towards a general strategy of architectural and urban conservation for historical cities in Libya GhadamesLibya, 27-29/10/2007.

[13] N. Dann, and D. Worthing, (2005) 'Heritage organizations and condition surveys', Structural Survey, 23(2), pp. 91-100.

[14] A. ICOMOS, (1999) 'the Burra Charter for the Conservation of Places of Cultural Significance'. Australia. Available at: http://australia.icomos.org/.

[15] B. Gupta, L. Iyer, and J. Aronson, (2000) 'Knowledge management: practices and challenges', Industrial Management \& Data Systems, 100(1), pp. $17-21$.

[16] H. Scarbrough, J. Swan, and J. Preston, (1999) Knowledge Management: a literature review. London: Institute of Personnel and Development.

[17] G. Bock, G., Zmud, R., Kim, Y., and Lee, J. (2005) 'Behavioral intention formation in knowledge sharing: Examining the roles of extrinsic motivators, social-psychological forces, and organizational climate ', MIS Quarterly: Management Information Systems 29(1), pp. 87-111.

[18] I. Nonaka, and H. Takeuchi, (1995) The Knowledge-Creating Company: How Japanese Companies Create the Dynamics of Innovations. Oxford, UK: Oxford University Press.

[19] J. Rowley, (2001) 'Knowledge management in pursuit of learning: the Learning with Knowledge Cycle', Journal of Information Science 27 (4), pp. 227-237.

[20] T. Davenport, and L. Prusak, . (2000) 'Working Knowledge: How Organisations Manage What They Know', [Online].Available at: http://wang.ist.psu.edu/course/05/IST597/papers/Davenport know.pdf.

[21] T. Sheehan, D. Poole, I. Lyttle, . and C. Egbu, . (2005) 'Strategies and Business Case for Knowledge Management', in Anumba, C., Egbue, C. and Carrillo., $\mathrm{P}$ (ed.) Knowledge management in Construction. Oxford: Blackwell Publishing Ltd, pp. 50-64.

[22] D. Snowden, . (1999) 'Liberating Knowledge', in Reeves, J.E. (ed.) Liberating Knowledge. London: Caspian Publishing, pp. 6-19.

[23] Fellows R., A. Liu (ed.) (2003) Research methods for construction 2nd edition ed Oxford: Blackwell.
[24] P. Quintas, . (2005) 'The Nature and Dimension of Knowledge Management', in Anumba, C., C. Egbue, P. Carrillo (ed.) Knowledge management in Construction. Oxford: Blackwell Publishing Ltd, pp. 10-30.

[25] P. Goodman, and E. Darr . (1998) 'Computer-aided systems and communities: mechanisms for organizational learning in distributed environments', Management Information Systems Quarterly, 22(4), pp. 417 440.

[26] K. Andrews, and B. Delahye (2000) 'Influences on knowledge processes in organizational learning: the psychosocial filter', Journal of Management Studies, 37(6), pp. 797-810.

[27] BS7913 (1998) British Standards Institution, guide to the principles of the conservation of historic buildings, London

[28] B. Feilden, (2004) Conservation of Historic Buildings. London: Architectural Press.

[29] I. Hume, (2007) 'the philosophy of conservation engineering', in Forsyth, M. (ed.) Structure \& Construction in Historic Building Conservation. Oxford: Blackwell Publishing Ltd, pp. 12- 18.

[30] A. Al-Ghassani, C. Anumba, P. Carrilo, and H. Robinson, (2005) 'Tools and Techniques for Knowledge Management', in Chimay J. Anumba, C. (ed.) Knowledge management in Construction. Oxford: Blackwell Publishing Ltd, pp. 83 - 102.

[31] J. Bishop, (2009) Managing Technical Knowledge to Enhance Organisational Best Practice. Loughborough University [Online]. Available at: https://www.lboro.ac.uk/cice/research/theses/30_thesis.pdf

[32] S. Kooh, . andJ. Altmann, . (2017) How Organizational Structure Affects Organizational Learning, Journal of Integrated Design and Process Science, 21 (1) pp. 43-60

[33] V. Anantatmula, (2008) 'Leadership role in making effective use of KM', The Journal of information and knowledge management systems, 38 (4), pp. 445-460.

[34] R. Beijerse,. (1999) 'Questions in Knowledge Management: Defining and Conceptualising a Phenomenon', Journal of Knowledge Management, 3(2), pp. $94-109$.

[35] N. Dann, and S. Wood, (2004) "Tensions and omissions in maintenance management advice for historic buildings', Structural Survey, 22(3), pp. 138 $-147$

[36] J. Rowley, (2000) 'From learning organization to knowledge entrepreneur', Journal of Knowledge Management, 4(1), pp. 7-15.

[37] G. Murthy, and S. Panchal, (2011) A presentation on a comprehensive project on knowledge management. Available at: http://www.scribd.com/doc/74667358/8/the-core-components-of$\mathrm{km} \#$ page $=35$.

[38] S. Bano, and M. Khan, (2010) 'Study of factors that impact knowledge management fit in the corporate sector of Pakistan', Far East Journal of Psychology and Business, 1(1), pp. 15-31.

[39] M.Shin, T. Holden, and R. Schmidt, (2001) 'From knowledge theory to management practice: towards an integrated approach', Information Processing and Management, (37), pp. 335-355.

[40] J. Brown, and P. Duguid, (1991) 'Organizational learning and communities-of-practice: towards a unified view of working learning and innovation.', Organizational Science, 2(1), pp. 40-57.

[41] D. Dougherty, (1992) 'Interpretative barriers to successful product innovation in large firms.', Organization Science, 3(2), pp. 179-202.

[42] J. Hahn, and M. Subramani, (2000) 'A framework of knowledge management systems: issues and challenges for theory and practice', Knowledge Management Systems, pp. 302-312.

[43] S. Newell, M. Bresnen, L. Edelman, H. Scarbrough, and J. Swann, (2006) 'Sharing Knowledge Across Projects Limits to ICT-led Project Review Practices', Management Learning, 37(2), pp. 167-185.

[44] A. Kianto, M. Vanhala, and P. Heilmann, (2016) "The impact of knowledge management on job satisfaction", Journal of Knowledge Management, 20 (4) pp.621-636.

[45] C. Egbu, S. Hari, and S. Renukappa, (2005) 'Knowledge management for sustainable competitiveness in small and medium surveying practices', Structural Survey, 23(1), pp. 7- 21.

[46] T. Sheehan, D. Poole, I. Lyttle and C. Egbu (2005) 'Strategies and Business Case for Knowledge Management', in C. Anumba, C. Egbue and P. Carrillo (ed.) Knowledge management in Construction. Oxford: Blackwell Puplishing Ltd, pp. 50-64.

[47] C. Joe, P. Yoong, and K. Patel, (2013) "Knowledge loss when older experts leave knowledge-intensive organizations", Journal of Knowledge Management, 17 (6) pp.913-927 